\title{
MONTAIGNE, LEITOR DE SI PRÓPRIO
}

\author{
Rodrigo Labriola \\ rlabriola@gmail.com
}

Embora bastante longínquas no tempo, amiúde algumas leituras determinam percursos estranhos no esforço por comentar de forma escrita as outras mais recentes. É sabida a má fama dos comentários desde que George Steiner ousou comentar contra os comentadores atuais das universidades. Mas também parece-me ainda atinada a frase de André Gide: "Permanecemos sempre em débito com Montaigne (...) Cada qual respiga nele o que mais lhe apetece e que não raro é o que outro menosprezou. Nenhum autor será mais facilmente invocado sem perigo de traição..." (MONTAIGNE, 1953, p. 31). Não se trata, porém, de negar a possibilidade da crítica, mas de esclarecer que o exíguo recorte dos Essais que pretendo comentar procura ilustrar um certo percurso tramado pelo acaso das velhas e novas leituras que se suscitaram sobre os Ensaios de Michel de Montaigne. Nesse sentido, redirecionando velhas e novas leituras, é que funcionaram os conceitos tecidos por Luiz Costa Lima em Limites da Voz (cuja primeira edição data de 1993, sendo a segunda revisada de 2005) e em um artigo posterior intitulado "Montaigne: a história sem ornatos" (2006), que retoma a tese daquele livro e aprofunda um dos seus filões analíticos. De maneira particular, esses textos do ensaísta brasileiro estimulam a polêmica e entrecruzam seus fios com um debate teórico mais abrangente, desenvolvido sobre as problemáticas do estatuto do sujeito moderno, o surgimento da literatura, 
e as condições de possibilidade do conhecimento (e da história) depois do século XVI. As reflexões sobre os Ensaios aqui expostas, então, vão paulatinamente girando em torno de algumas das proposições críticas de Costa Lima.

Como exemplo das curiosas reviravoltas a que estamos expostos quando citamos os Ensaios, poderiam ser citadas algumas das palavras de Montaigne sobre a ciência: «É em verdade a ciência coisa importante e útil. Os que a desprezam dão prova de estupidez. Não considero, entretanto, seu valor tão elevado quanto o imaginam alguns (...) ou como outros que nela veem a mãe de todas as virtudes, resultando da ignorância todos os vícios. Se assim é, cabe interpretá-lo.» (MONTAIGNE, II, 12)ํ. Porém, a ciência à qual Montaigne se referia não é a do paradigma epistêmico moderno surgido depois dele, e da qual o atual "cientificismo" talvez seja seu canto de cisne. Os «homens de ciência» — dos que Montaigne diz: «os aprecio muito, mas não os adoro» - eram letrados, cuja prática intelectual se achava enquadrada no modelo da escrita retórica e concentrada no conhecimento da teologia; aliás, desses «doutos» era que seu pai «recolhia seus preceitos e discursos como oráculos e com tanto maior reverência e fé quanto não estava à altura de julgá-los, não tendo tido, como não tiveram seus avós, íntimo contato com as letras». As citações correspondem aos primeiros parágrafos de um dos primeiros ensaios escritos por Montaigne (Cf. GIDE, 1953 e MILLIET, 2000), ainda que o colocasse mais tarde no segundo livro; trata-se da apologia de Raymond Sebond, que escreveu uma Theologia Naturalis, traduzida por Montaigne a pedido do seu pai em 1567; além disso, esse capítulo "figura entre aqueles em que o pensamento de Montaigne, tão desordenado e naturalmente erradio, esforça-se mais seriamente por desenvolver uma

1 Salvo onde se indica expressamente, as citações dos Ensaios de Montaigne em que apenas são mencionados os números do livro e do capítulo, que estão entre aspas francesas, referem-se à edição traduzida para o português por Sergio Milliet (200o), cujos dados completos se consignam na bibliografia. Esta tradução reproduz o texto dos Essais de conformidade com a edição modernizada por Albert Thibaudet e Maurice Rat (Pléiade, Paris, 1965) e Milliet esclarece a posterior consulta com os estudos de Pierre Villey, cuja versão foi publicada em 1965 e a última edição é de 1999 (Quadrige, P.U.F., Paris). No entanto, os argumentos desenvolvidos na parte final deste escrito baseiam-se na edição eletrônica in progress de Guy de Pernon, que leva em conta todas as versões anteriores em francês - as datas do início da disponibilidade para sua consulta on-line foram as seguintes: para o Livro I, PDF de junho de 2004, WEB de novembro de 2004; para o Livro II, WEB de janeiro de 2006. As referências completas desse recente trabalho se acharão na bibliografia; as traduções para o português a partir deste texto são minhas, infelizmente. 
espécie de doutrina e por dar aparente consistência a seu inconsistente ceticismo". A conclusão planejada de André Gide a respeito de tal avaliação diverte ao leitor: "Seu pensamento [o de Montaigne] perde aqui toda sua graça, todo encanto...” (MONTAIGNE, 1953, p. 15).

Geralmente, os leitores modernos perceberam nos ensaios de Montaigne uma multidão de digressões e contradições que, afundados na episteme científica, atribuiriam ao ceticismo e ao conservadorismo decorrente, em algumas ocasiões; ou quiçá a um relativismo extremado em outras; ou ainda, noutras, à busca de uma originalidade própria de cada pessoa (subjetividade). O último é especialmente o ponto de contato que liga duas das melhores leituras de Montaigne: a realizada por Gide com a feita por Maurice Merleau-Ponty. Embora divergentes em quase tudo, tanto um quanto outro vislumbram o problema das digressões e contradições em Montaigne - que parece ser o nó górdio que estimula todas as penas - como produto de um tipo de Eu que as preexistia e que seria o mesmo Eu que escreve. No caso de Merleau-Ponty, trata-se de uma "experiência de si próprio" (Cf. 1960, p. 252). Il a cherché et peutêtre trouvé le secret d'être, dans le même temps, ironique et grave, libre et fidèle. (Idem, p. 266) Por isso, Merleau-Ponty encontra uma constante somente na consciência de si, pois — diferente de Descartes, e semelhante à Pascal - esse Eu careceria de um objeto exterior de conhecimento. No caso de Gide, Montaigne escreve assim porque aceita previamente ("ter aceito") "as contradições de seu próprio eu”. Ainda mais, daria a sensação de que para Gide o "problema essencial" do Eu ("o ser humano") irá sendo "ventilado" através da arte literária ao correr dos séculos, i.e. que essa humanidade é imutável ou então já estava pronta em Montaigne, apenas faltava que evoluísse a psicologia no âmago das obras (de ficção, acrescentaria eu). Mas observemos, sobretudo, que nos dois textos mencionados, a contradição ou a inconstância na materialidade da escrita da obra de Montaigne permanecem inexploradas, já que são remitidas a um momento prévio no qual se postulam como constitucionais do Eu - talvez daí as caracterizações como "segredo de ser" ou "problema essencial” que é "muito mais do que apenas a inconstância”.

\section{II}

Entendo aqui por materialidade da escrita as relações triplas entre uma forma textual, as formações discursivas no contexto social, e a historicização de suas condições de produção e de recepção. A definição pode resultar ampla demais, mas penso que nessas coordenadas se 
insere Limites da Voz de Costa Lima, por isso também quis comentar os dois textos anteriores (que estão fora desse quadro teórico), a fim de melhor marcar as diferenças com a complexa tese de Costa Lima, que no primeiro capítulo - intitulado "A sagração do indivíduo" aborda a obra de Montaigne. Como já antecipei, o livro todo se debruça sobre o sujeito moderno, o surgimento da literatura e da crítica, e as condições de possibilidade do conhecimento (e da história) depois do século XVI. (Nesse sentido, não é um livro específico.) Mas contra o que poderia parecer em um primeiro e rápido olhar sobre esses temas, a obra de Montaigne não é um pretexto nem um conjunto de exemplos para corroborar teorias alheias. Ao contrário, os conceitos gerados durante a crítica vão surgindo com a leitura de Montaigne. (E nesse sentido, sim, é um livro específico.) Eis uma excelente síntese disso: "O que nele de fato se tem é uma teoria da Modernidade, ou melhor: uma teoria da Literatura como teoria da Modernidade" (Dolabela, 2005, p.1).

Bosquejarei um resumo pessoal dessas primeiras cem páginas, discreto quanto aos temas:

a) Ao contrário do sujeito (subditus) antigo e medieval, cuja individualidade estava regida pelo nexo que o ligava a seu grupo social - sujeito hetero-dirigido, ordem da mímesis (semelhança), modelo retórico dos exempla, mundo substancialista, teocentrismo - , o sujeito moderno se autonomiza do grupo e progressivamente vai se colocando no centro - indivíduo psicologicamente orientado, ordem do método, crise do modelo retórico, quebra da exemplaridade, mundo heterogêneo, antropocentrismo.

b) Nos ensaios de Montaigne, apresenta-se a afirmação individualista do sujeito moderno, mas o paradigma epistêmico (a Lei, que determina os limites do pensável, nos termos de Costa Lima) ainda não está consolidado, pois não dispõe de um princípio homogeneizador do Real coerente com a nova primazia do sujeito autônomo ("o mundo transformara-se de repente em um infinito conjunto de singularidades; assim o conhecimento é impossível"; Funes el Memorioso).

c) Mas nesse momento inicial da autonomia do sujeito, na exigência que implica escrever um retrato de si (exploração do vazio deixado pelo fracasso do retrato do amigo morto, La Boétie), Montaigne vai ensaiando com tateios da forma, pois ainda o modelo da escrita autobiográfica é inexistente (atenção: as "confissões" de Santo Agostinho não contam devido a seu caráter "comemorativo", i.e. pela sua exemplaridade da ordem da mímesis). O resultado, portanto, é que os Essais são um texto 
em construção permanente, cujas sucessivas modificações ao longo das edições de 1580, 1588, 1595 (sem deixar de fora, acrescento eu, as anotações manuscritas do Exemplar de Bordeaux) servem para avaliar os "progressos" da relação de uma nova forma (o ensaio) com um novo conteúdo (o Eu).

d) O ideal do retrato é a exata representação, essencial e sem ornatos, do Eu (como os outros nos vêem) que, por sua vez, é comandado pela consciência que determina o "ideal do Eu" (como queremos ser vistos). Num começo, então, Montaigne adota um método duplo: abandono da retórica e conhecer-se pela percepção consciente. No entanto, o ideal do Eu fracassa junto com o ideal do retrato. É impossível construir na escrita um retrato fixo comandado pela consciência, pois a subjetividade ainda carece da Lei, não tem a estabilidade necessária para afixar o conhecimento do Eu em um discurso autobiográfico, diria eu. O devir permanente da forma coincide com a mutação permanente do "objeto" (anacronicamente falando) que é o próprio sujeito.

e) Portanto, não só não há possibilidade prévia à escrita de conhecer o Eu, mas (além disso) a escrita vai construindo o único Eu (o Eumovente) que pode ser mostrado, um Eu sempre em fuga. Ou seja: o sujeito psicologicamente orientado nasce no devir permanente da escrita: a própria vida (do indivíduo) não se vê sem o hiato da escrita.

f) O ceticismo e o conservadorismo de Montaigne, e as contradições deles decorrentes, são ao mesmo tempo sintoma e reação de um momento prévio à legitimação da nova Lei. Embora a razão no seio do novo Eu não sirva para conhecer, ela pode ser útil do ponto de vista pragmático. A defesa dos costumes garante um mínimo de generalização para o agir cotidiano, e a razão sensata é um bom instrumento para defender a vida do seu portador.

g) Como conclusão, no derradeiro parágrafo desse primeiro capítulo de Limites da Voz dedicado a Montaigne, Costa Lima destaca que

...já não é suficiente contrapor os individualismos montaigniano e cartesiano. Em decorrência, se os Essais não oferecem uma teoria do conhecimento sistemática e legitimadora do eu, não deixam de conter elementos que estarão presentes naquela teoria e cuja articulação tem passado desapercebida. Destacam-se, como direções que a antecipam, a exaltação do fato e a suspeita da imaginação. Ambas poderiam ser detalhadas quanto à confecção do próprio retrato e na suspeita sobre os relatos de viagem. Como só o fizemos quanto ao primeiro ponto, ao menos agora se assinale: no momento em que a Europa era inundada pelos testemunhos sobre o Novo Mundo, Montaigne sublinha a necessidade de encarecer-se a autenticidade do que aí se dizia. (COSTA LIMA, 2005, p. 105). 
Até aqui, os limites da voz de Montaigne e o término dos Limites da Voz de Costa Lima quanto aos Essais. No entanto, «interpretar as interpretações dá mais trabalho do que interpretar a própria coisa, mas escrevemos mais livros sobre livros do que sobre os assuntos mesmos; comentamo-nos uns aos outros. Há excesso de comentadores mas escassez de autores. A principal ciência do século consiste em entender os sábios; não está nisso o fim último de nossos estudos?"» (MONTAIGNE, III, 13). Trago agora esta citação do último ensaio do último livro de Montaigne pois, junto com a primeira mencionada neste trabalho (I, 12; na seção 2), escoa bem na veia da qual tirarei o sangue: o assunto da interpretação dos escritos alheios e contemporâneos no século XVI e, especialmente, as mudanças que sobre isso poderiam ser conjeturadas em Montaigne. Para expressá-lo de uma outra maneira, duas perguntas:

a) O que significa para Montaigne colocar a frase «Se assim é, cabe interpretá-lo» em 1580, logo após uma crítica moderada aos literati e antes de um longo comentário sobre uma teologia?

b) E o que significa a frase «Interpretar as interpretações dá mais trabalho do que interpretar a própria coisa» no final da sua vida, logo depois de uma paráfrase de Orlando Furioso escrita por seu amigo La Boétie?

As respostas para estas duas perguntas estão enquadradas por dois tipos de explicações. As do lugar comum e a velocidade atribuem a Montaigne a subjetividade dos séculos posteriores avant la lettre (Cf. Taylor, 1989). As outras pensam a obra de Montaigne contextualizada no próprio século XVI, entre elas entraria a consideração do livro de Costa Lima.

\section{III}

Mencionemos primeiramente que Costa Lima procura ultrapassar a contraposição dos individualismos cartesiano e montaigneano. Visando a essa meta, o autor tira a obra de Taylor do jogo com a movida de xadrez das páginas 51 e 52 de seu livro, pois

sabendo-se que o Sources of self consagrará um capítulo a Montaigne poderse-ia esperar a superposição de sua tese geral com sua análise particular. Isso não deixa de se dar, porém de maneira que não chega a tornar bastante visível o hiato que procuramos. Taylor se contenta, reiterando a oposição usual entre Montaigne e Descartes... 
sem perceber que

...o autocentramento do sujeito permanecerá uma equação incompleta se não se lhe relacionar com um termo ausente que o abarque, salvo se, o que ainda não sucede com Montaigne, o indivíduo se tornar a si mesmo como base da Lei. (COSTA LIMA, 2005, p. 51-52).

O hiato procurado por Costa Lima não é uma simples fratura, é quase uma falha geológica que deixa à vista muitos filões. A exaltação do fato e a suspeita da imaginação são os dois elementos desapercebidos, e que não apenas antecipam a futura legitimação do Eu (junto com a subjetividade extrema, usualmente destacada), mas que sobretudo serão incorporados em uma teoria do conhecimento sistemática que entronize o indivíduo como sua base. Entretanto, esta idéia nada tem a ver com o truque do avant la lettre, porque esses elementos antecipatórios são descobertos dans la lettre, ou seja: a partir do famoso ceticismo montaigneano no âmago dessa subjetividade extrema, que em princípio pode parecer tão contraditória com a objetividade da ciência (agora sim no sentido moderno). Por isso, tal demonstração precisava ser feita sobre a confecção do próprio retrato de Montaigne, como se faz em Limites da Voz. É só a partir desse ponto que existe a possibilidade de pensar de maneira nova o assunto dos relatos de viagens em Montaigne, evitando impor sobre a sua letra certas cristalizações do discurso histórico (História) que se cumprirão a partir do século XVIII.

Ora, esse derradeiro caminho - que leva desde as referências nos Essais sobre o Novo Mundo rumo à concepção de história em Montaigne — não se achará em Limites da Voz. Os aprontes iniciais para essa viagem pertencem ao artigo "Montaigne e a história sem ornatos" (Costa Lima, 2006), no qual, depois de citar o ensaio II, 10 na parte concernente à história, indica que:

O elogio da história simples por Montaigne dependia pois de sua afirmação de um modo de composição não dependente do formato moralista-retórico. Mas não só ele não é explicitado pelo autor, como, o que é básico, sua formulação implicaria um empenho teórico-filosófico de todo alheio à abordagem montaigniana. (COSTA LIMA, 2006, p. 4).

Daí que, depois de considerar o caminho já traçado em Limites da Voz, em relação ao Eu e à sagração do indivíduo, Costa Lima propõe "pensar a relação entre ideal do eu, ideal do retrato e seu fracasso quanto ao tipo de história que Montaigne favorece desde a primeira versão dos 
Ensaios" (Idem, p. 7). É obvio que o ideal do eu (e do retrato) se adequava ao elogio da história simples, mas

A seu fracasso corresponderá alguma mudança? Em palavras bem explícitas: em termos de escrita da história, a que corresponderia a afirmação do eu como processo em devir, incapaz de ser apenas descrito, modificável à medida mesma se escreve? (sic. COSTA LIMA, ibid.).

Por último, admitindo que uma tal pergunta não pode ter uma resposta taxativa, e depois de considerar a chamada "nouvelle histoire" de Pasquier et al., resolve:

É provável (...) que a história simples de Montaigne tenha surgido autonomamente. Teria então sido a própria ênfase montaigniana na concepção moderna do sujeito, psicologicamente orientada e não mais heterodirigida, antecipadamente anticartesiana, que estabeleceu uma ponte com as investigações daqueles seus menos afortunados contemporâneos. Voltando pois à pergunta de que já dissemos não admitir resposta definitiva, podemos pois supor que, ao fracasso do ideal do retrato, não tenha correspondido, em Montaigne, uma concepção mais elaborada da história. (Costa Lima, 2006, p. 8).

Todavia, penso que seria possível indagar ainda mais e talvez dar uma maior complexidade à concepção de história por parte de Montaigne. Sem descuidar que

Contra infundadas esperanças, logo se advirta: para que a pergunta encontrasse uma resposta taxativa, seria preciso esquecer o que já sabemos: (a) que Montaigne não é exatamente um pensador, muito menos que nunca cogitou de ser um teórico da história; (b) que Les Essais não fosse o resultado de uma experimentação - como dizer de si, enquanto produto de uma ausência-quetrabalha? Mas só agora a advertência encaminha para seu principal alvo: é a própria falta de "correção" da história simples, i.e., não retoricamente ataviada, presa ao horizonte do factual, procurando reproduzir em palavras uma cena do passado, que torna essa indagação instigante. (COSTA LIMA, 2006, 7).

Assim, sendo, caberia a análise se perguntar, a seguir, qual seria a condição de possibilidade de história decorrente da progressiva geração do Eu-movente. Para isso, porém, deveríamos antes retomar o tema da interpretação, pois - como disse Costa Lima - Montaigne nunca cogitou em ser um teórico da história, e ainda menos (acrescento eu) um historiador sequer de acontecimentos parciais de sua época. E então, que vínculo material teria tido Montaigne com a história? Não a escrita, por certo, mas a leitura. 


\section{IV}

Imaginemos (por enquanto só isso) um Montaigne-leitor... Tentarei esclarecer a pertinência da imaginação e das reticências nesta proposta. Em primeiro lugar, cumpre esclarecer que não se trata da leitura-de-Montaigne ${ }^{2}$ sobre tal ou qual texto, nem das diferentes leituras simultâneas, tampouco das variações verificáveis no tempo comparando uma leitura $X$ com outra $Y$. Em todos esses casos, constatamos um conteúdo ${ }^{3}$ em $X$ e um mesmo ou outro (conteúdo) em $Y$, postulando uma variação contínua ou fragmentária das leituras-deMontaigne (“leituras de Montaigne sobre...”). Analiticamente falando, só podemos interpretar textos. E se, em vez de interpretar, procuramos as condições de possibilidade do sentido, é também porque o texto está aí e interpretamos as interpretações desse ou de outros textos, ad infinitum. O grande ausente, porém, é o ato, que se perdeu no passado. ${ }^{4}$

Em segundo lugar, parece-me que no cerne da análise estabelecemos sempre um hiato mais ou menos distante entre leitura e escrita. É o vazio do ato que determina a condensação de pontos fixos (conteúdos) que podemos remitir alternativa e conceitualmente à leitura ou à escrita. ${ }^{5} \mathrm{~A}$ vantagem da imaginação, então, reside em me permitir colocar a ênfase sobre os atos, já que, ainda eles sejam eles inatingíveis, ela é capaz de gerar uma imagem de Montaigne na ação de ler. Por outro lado, sabe-se que todo texto é o resultado de um processo conjunto de leitura e escrita. Portanto, o ato representado nessa imagem complementa-se com $a$ ação de escrever.

Daí que, em terceiro e último lugar, a fim de diminuir ao mínimo o hiato leitura-escrita, o interrogante seja: qual é o ato imaginável em que essas duas ações estariam mais próximas? Certamente não seria um, mas muitos. Todavia, no caso dos Essais (tão cheios de acréscimos

2 Existe uma inquietante ambiguidade nos genitivos; neste caso, "leitura-deMontaigne" se refere às leituras que são feitas por Montaigne e não as que são feitas dele.

3 Como forma ou como substância, segundo o sistema de Hjelmslev. Para desenvolver e criticar este ponto, dever-se-ia considerar o artigo "O campo não-hermenêutico ou a materialidade da comunicação” de Hans Ulrich Gumbrecht. (GUMBRECHT, 1998, p. 137-151)

4 Ato, aqui, não apenas significa o ato da enunciação, mas qualquer ação em geral considerada em sua materialidade. De novo seguindo os termos de Hjelmslev e a proposta de Gumbrecht (Ibidem), quiçá caracterizaria o conceito de "forma da expressão".

5 Devido a esta última questão, leitura e escrita só podem ser vinculadas entre si por meio de mecanismos mais ou menos teóricos. Observemos ainda que cada um dos "mais ou menos" das últimas sentenças não implica mera vagueza, mas indica a aceitação do problema como irresoluto. 
e modificações; work in progress numa época em que o autor moderno ainda não existe) a escolha do ato da correção parece a mais adequada. Assim, o Montaigne-leitor que imagino é primeiramente um Montaigne na ação de corrigir; i.e. o momento no qual ele lê seu próprio texto e o corrige escrevendo de novo. Tal imagem constitui o alicerce dos meus argumentos - penso que, se quando procuramos pedras, a experiência nos demonstra que apenas conseguimos construir sobre areia, talvez seja melhor edificar diretamente no ar. Seja como for, é importante esclarecer aqui que - nos poucos fragmentos que citarei neste trabalho - a parte escrita da "correção" corresponderia quase exclusivamente aos acréscimos, mais do que às emendas, rasgaduras ou rescritas. ${ }^{6}$ Em suma, minha intuição é que chez Montaigne o percurso que leva do "ideal do Eu" para o Eu-movente, tramado inseparavelmente na escrita com a passagem do "ideal do retrato" para a o resultado final do ensaio inscrito no horizonte autobiográfico (Cf. COSTA LIMA, 2005), cumprir-se-ia simultaneamente a um devir do Eu na leitura.

Vejamos agora esta proposta no ensaio I, 9, Dos mentirosos. O texto é um verdadeiro mosaico de tempos, e curiosas reflexões podem ser suscitadas quando compararmos as diferentes edições.7 Serei telegráfico para evitar mal-entendidos. O início corresponde a 1580:

Il n'est pas un homme à qui il convient moins que moi de vouloir parler de la mémoire : je n'en trouve quasi pas trace en moi, et je ne pense pas qu'il y en ait une autre au monde qui soit aussi étonnamment défaillante. Toutes mes autres facultés sont médiocres et banales, mais pour celle-là, je pense être exceptionnel et très rare, et digne en cela de me faire un nom et une réputation. (MONTAIGNE 1580, I, 9, § 1.). ${ }^{8}$

6 Remanesce em um ar como que rarefeito refletir sobre a abundância de acréscimos em relação à curiosa escassez das emendas, rescrita e rasgaduras, nos inícios da subjetividade.

7 Utilizarei a versão modernizada por Guy de Pernon, que leva em conta todas as versões anteriores em francês. Deixarei o texto na língua original para que seja melhor avaliado; quando o considere necessário pela complexidade do parágrafo, indicarei minha tradução para o português ou colocarei em nota de rodapé o texto original das edições de 1580, 1588, 1595 ou bem o Exemplar (manuscrito) de Bordeaux (circa 1592). Para facilitar o seguimento do argumento, a tipografia normal corresponde à edição de 1580; os negritos à edição de 1588; e os itálicos às notas manuscritas acrescentadas no Exemplar de Bordeaux.

8 Todas as citações de Montaigne que aparecem em francês correspondem à versão de Guy de Pernon (MONTAIGNE, 2004-2006), já mencionada na nota de rodapé 1. Para facilitar a localização temporal, junto ao nome de Montaigne aparece o ano da edição original, os dados de livro e número de ensaio, e o número do parágrafo desta nova edição eletrônica. 
Supomos que na data desta escrita ainda está vigente o "ideal do retrato" e, com ele, o "ideal do Eu". Nesta pintura, Montaigne tem falta de boa memória, como diríamos hoje, ou melhor: é uma memória fraca, que "desmaia”, ou seja, que se dilui no tempo, mas será uma memória em devir? - esta pergunta é muito importante; por enquanto, permanecerá em suspenso.

Logo depois do parágrafo anterior, na segunda edição de 1588, Montaigne inserta:

Outre l'inconvénient naturel que cela me cause (...) si en mon pays on veut dire qu'un homme n'a point de sens, les gens disent qu'il n'a point de mémoire. Et quand je me plains du défaut de la mienne, ils me reprennent et refusent de me croire, comme si je m'accusais d'être un insensé: ils ne voient pas de différence entre mémoire et intelligence.

C'est bien aggraver mon cas et me faire du tort, car à l'expérience, on voit plutôt, au contraire, que les mémoires excellentes se trouvent généralement chez les simples d'esprit. Et par dessus le marché, alors que je ne sais rien faire de mieux que de pratiquer l'amitié, ce sont les mêmes mots dont on se sert pour accuser mon mal et désigner l'ingratitude! On s'en prend à mon affection, et de là à ma "mémoire "; d'un défaut de ma constitution, on fait un défaut de ma conscience. (MONTAIGNE 1588, I, 9, § 2-3.).

Agora, a memória tem se tornado mais complexa. Entra em relação com o esquecimento de maneira inseparável; ainda mais, pode ser confundida com a "insensatez", caso não seja levada em conta a diferença entre memória e razão ("inteligência”, entendimento). Não é loucura, é um "defeito da consciência", uma doença constitutiva. Mas a crise se estabelece com a prática da amizade, que está na origem do ideal do retrato e do ideal do Eu. Então, estamos aqui diante de uma estranha simbiose. Em 1580, "o nome e a reputação" que eram mais neutras — nem boas nem ruins, apenas a descrição de um traço de raridade, contraposto à banalidade das suas outras faculdades —; agora, acrescentam-se os inconvenientes e começa o movimento do $\mathrm{Eu}$, mas na escrita o "ideal do eu" (como eu quero que me vejam) opera como um controle da diferenciação entre memória e razão.

Mas isso não é tudo. Remontemos no tempo até 1580 para comprovar o peso significante dos acréscimos. Com efeito, Dos mentirosos passava diretamente do § 1 para o § 9 da edição de 1595; em 1588 tinha inserido cinco parágrafos; circa 1592 colocara mais dois, alongando os anteriores de 1588; os parágrafos originais aparentemente não sofreram modificações. Enfim, depois daquele breve primeiro parágrafo dedicado à sua memória fraca, em 1580 dizia: 
Ce n'est pas sans raison qu'on dit que celui qui n'a pas une bonne mémoire ne doit pas s'aviser de mentir. Je sais bien que les grammairiens font une différence entre «mensonge » et "mentir » : ils disent qu'un mensonge est une chose fausse, mais qu'on a pris pour vraie, et que la définition du mot « mentir » en Latin, d'où vient notre Français, signifie « aller contre sa conscience »; que par conséquent, cela ne concerne que ceux qui disent ce qu'ils savent être faux, et qui sont bien ceux dont je parle. Or ceux-là, ou bien inventent de toutes pièces, ou bien déguisent et modifient quelque chose qui était vrai à la base.

Quand ils déguisent et modifient, si on les amène à refaire souvent le même récit, il leur est difficile de ne pas se trahir, parce que ce qu'ils racontent s'étant inscrit en premier dans la mémoire et s'y étant incrusté, par la voie de la connaissance et du savoir, il se présente forcément à l'imagination, et en chasse la version fausse, qui ne peut évidemment y être aussi fermement installée. Et les circonstances de la version originelle, revenant à tout coup à l'esprit, font perdre le souvenir de ce qui n'est que pièces rapportées, fausses, ou détournées.

Quand ils inventent tout, comme il n'y a nulle trace contraire qui puisse venir s'inscrire en faux, ils semblent craindre d'autant moins de se contredire. Mais ce qu'ils inventent, parce que c'est une chose sans consistance, et sur laquelle on a peu de prise, échappe volontiers à la mémoire, si elle n'est pas très sûre.

(MONTAIGNE 1580, I, 9, § 9-10-11.).

Observemos que, em 1580, o tema geral que ocupava o autor era bem simples: Montaigne pretende falar dos mentirosos; o parágrafo sobre a memória é apenas uma introdução que serve para justificar com o retrato do Eu um lugar comum. Logo, deve estabelecer a exatidão do ideal do retrato, pois o Eu poderia se perder entre os mentirosos do lugar comum, então recorre aos gramáticos: diferencia a mentira do ato de mentir, que é "ir contra a própria consciência". Por último, os mentirosos, que inventam ou modificam "qualquer coisa que é verdadeira na base". E pior: repetem a mentira muitas vezes com pequenas modificações; é aí quando a imaginação faz seu trabalho sobre a memória, et les circonstances de la version originelle, revenant à tout coup à l'esprit, font perdre le souvenir de ce qui n'est que pièces rapportées, fausses, ou détournées. Ora, o que seria essa "verdade de base"? Suponho que seria aquilo que hoje costumamos chamar de "os fatos", pois os mentirosos que inventam "tudo" estão menos expostos à contradição, e também - dado importante - porque da verité só falará oito anos depois! Nada a respeito dela aparece nos últimos parágrafos de 1580 .

Em resumo, a memória da primeira versão é plana e elementar: o que interessa é falar dos perigos da imaginação, que vão contra o que é "verdadeiro na base". Já então é mais observável a complexidade crescente que mencionáramos a respeito do parágrafo inserido em 1588. 
Como já explicáramos, Montaigne fez acréscimos que tiram a memória do estado de simples traço do retrato, entrando também no jogo a razão e o esquecimento. A memória simples como traço do ideal do retrato se expande pela pressão do ideal do Eu, em uma época na qual a estabilidade do próprio Eu que escreve já é duvidosa.

O enredo revela-se ainda mais interessante depois, quando desfiamos os parágrafos seguintes entre a edição de 1588 e o Exemplar de Bordeaux. ${ }^{9}$ Sumariamente: a complexidade da memória cresce ainda mais. Em 1588, já não é suficiente a desculpa com os amigos. Lembremos que o projeto do ideal do Eu está operando no parágrafo anterior. Aparece, então, o esquecimento como uma vantagem precisamente para a escrita do retrato! No que tange à forma, esquecer contribui para a mesura ("discrição"), pois existe o perigo da "invenção" (a imaginação) referida à pintura do retrato (neste caso na parte do "temperamento"). Eis o discurso mesurado a fim de evitar a ornamentação de si próprio com a imaginação.

Ainda há algo a mais, porém. A palavra "invention" estaria ligada também à imaginação ou à fantasia que proliferam nas narrativas, tanto nas dos mentirosos como nas que se dão no âmbito mais restrito da amizade. O parágrafo seguinte pertence a 1588 e prosseguia a seguinte frase: Et mon discours en est plus mesuré, car le magasin de la mémoire est généralement bien mieux fourni que ne l'est celui de l'invention...

Et c'est tant mieux!... J'en vois la preuve chez certains de mes meilleurs amis: comme leur mémoire leur fournit les choses en entier et comme présentes, ils font commencer leur narration de si loin en arrière, et la chargent de tant de circonstances inutiles, que si l'histoire était bonne, elle s'en trouve comme

9 Transcrevo-os em bloco para melhor comparar: Certes, je peux facilement oublier; mais pas négliger ce dont un ami m'a chargé. Qu'on se contente de mon handicap, sans en faire une sorte de méchanceté! et une méchanceté si éloignée de mon tempérament... Je me console pourtant un peu, en me disant que c'est un mal dont j'ai surtout tiré le moyen d'en corriger un pire, et qui se serait facilement développé chez moi : à savoir, l'ambition. Car mon handicap est rédhibitoire pour qui veut se mêler de relations publiques. // Et comme le montrent plusieurs exemples du même type où la nature a fait son œuvre, à mesure que cette faculté s'est affaiblie, elle en a fortifié d'autres: je laisserais facilement reposer et s'alanguir mon esprit, comme font les autres, sans chercher à l'exercer, si les idées nouvelles et les opinions des autres m'étaient fournies par la mémoire. Et mon discours en est plus mesuré, car le magasin de la mémoire est généralement bien mieux fourni que ne l'est celui de l'invention. Si la mémoire m'eût secouru, j'eusse assommé tous mes amis de mon bavardage, car bien des sujets, éveillant en moi cette faculté que j'ai de les manier et de les employer, eussent suscité et activé mes discours. (MONTAIGNE 1588 e Ex.de B, I, 9, § 4-5.). 
étouffée, et que si elle ne l'était pas, vous maudissez bientôt, ou la qualité de leur mémoire, ou la médiocrité de leur jugement. (MONTAIGNE 1588, I, 9, $\S 6$.$) .$

Uma elucidação: há uma contradição entre este parágrafo (sobre a suposta "qualidade da memória") e aqueles que em 1588 vêm imediatamente depois (§ 9-10-11) sobre os mentirosos. Porém, os problemas que começam a ser vislumbrados são os sistemas da leitura e da escrita. Lembremos ainda que, na versão de 1588 , a erupção do problema da memória chega junto àquele da razão e do esquecimento. Portanto, a ideia da palavra "invention" se monta primeiro sobre o texto anterior que suspeitava da imaginação, e só em segundo lugar assume o papel do diabo na defesa do estilo mesurado de escrita (§ 4-5). É lógico: Montaigne não pretende acusar seus amigos reais de mentirosos (§ 6), mas de ter uma memória tão boa que não poderão prescindir de sua amizade nos assuntos que exijam a razão (Cf. $\S 2) .{ }^{10}$

Com os acréscimos do manuscrito de Bordeaux, vemos que também entram no jogo as "relações públicas" (Cf. § 4). Se até 1588 bastava controlar a memória e as narrativas mediante a razão simples no âmbito da amizade, depois de 1588 o mundo público maior (onde aparece a "ambição") traz consigo o problema da "razão sensata" como afirma Costa Lima - e do juízo próprio perante as "novidades e opiniões dos outros". Duas edições têm sido publicadas; com certeza Montaigne deve ter recebido comentários críticos. Desta maneira, agora, é tão só o esquecimento que ajuda tanto o entendimento quanto o método da escrita, em uma época na qual há uma aceitação do Eumovente e do fracasso do ideal de Eu. Isto, já que depois de "exercer sua razão (esprit)" prossegue o trecho de 1588 sobre o estilo da escrita mesurada, que termina com o perigo da invenção. Havendo chegado a este ponto ( $(5)$, Montaigne acrescenta no Exemplar de Bordeaux que «se a memória tivesse me salvado, eu teria aturdido todos meus amigos com a minha conversa, porque muitos tópicos, enquanto despertando em mim esta faculdade que eu tenho para controlá-los e usá-los, teria causado e ativado minhas falas» (tradução minha). Em outras palavras: os acréscimos têm alterado todo o sentido das frases, depositando uma nova camada de significação. Circa 1592, a memória é um assunto público

1o Destaquemos en passant que, embora Montaigne concedesse primazia à escrita, na época vigorava o modelo retórico e uma visão do mundo que privilegiava a oralidade, porquanto as palavras referidas à fala não necessariamente deixariam de fora sua aplicação à escrita (Cf. MENDIOLA, 2003). 
e social, e os discursos próprios e alheios podem se transformar em uma retórica (Cf. a continuidade dos $\S$ 4-5-6 na edição de 1595). Assim, a palavra "invention", que antes estava ligada à imaginação e à fantasia, agora se transforma na inventio retórica ligada à memória. Por sua vez, a memória ofusca o juízo do entendimento (a razão), traindo o modelo da mesura (diferente da discretio) que procurava uma forma descarnada, mais apegada aos fatos e à verdade. De repente, a memória (que nunca foi muito cara a Montaigne) alia-se à suspeitosa imaginação e se revela já não como obstáculo, mas como uma verdadeira inimiga da sua obra, pois vem junto com todo o arsenal da retórica. Uma vez fracassado o ideal do Eu, ainda persiste a concepção de uma escrita capaz de exaltar os fatos... Parece que Costa Lima tinha razão, portanto, e a concepção de escrita da história como história simples persiste apesar da mutação do Eu. Mas uma pergunta se impõe: esses fatos a serem relatados são os mesmos fatos presentes no começo da escrita dos Essais? Poderia uma leitura gerar uma escrita deliberadamente antirretórica apoiada na história? Implicaria isso tudo a modificação da concepção da história?

Acrescentemos à análise um pouco de ficção. Imaginemos Montaigne, de novo, em 1590. Já se retirou da vida pública definitivamente e sabe que logo morrerá. Seu máximo interesse está nos ensaios. Não só efetua as últimas correções do Livro III (que permanecerá inédito até a edição de 1595), mas sobretudo relê a edição de 1588 dos Livros I e II. Neste preciso momento, está lendo Dos Mentirosos e acaba de fazer um acréscimo manuscrito que inclui deliberadamente uma condenação à retórica, especificamente com a transformação do significado da invenção para a inventio (§ 4-5) Tudo bem. Logo, continua sua leitura e cogita sobre o parágrafo que segue ao acréscimo, já impresso em 1588 (§ 6), e que claramente traz em si o tema da narrativa ("narration" e "histoire"). Montaigne condenara à inventio com o acréscimo manuscrito, mas também, devido a isso, o velho parágrafo de 1588 se ressignifica na sua leitura. Agora, não se trata apenas do problema da memória ou da imaginação nos discursos; a "narration" é a narratio como parte de um artifício retórico. A aposta tem se duplicado, mas por que não triplicá-la. Então escreve na margem:

C'est une chose difficile que de terminer un exposé, et de l'interrompre quand on est lancé. Il n'est rien où l'on reconnaisse mieux la qualité d'un cheval 
qu'en le faisant s'arrêter net. Même parmi ceux qui savent parler avec à propos, j'en vois qui voudraient terminer leur course, mais ne le peuvent pas. Pendant qu'ils cherchent l'endroit où s'arrêter, ils débitent des balivernes en traînant la patte comme s'ils défaillaient de faiblesse. Les vieillards, surtout, sont dangereux: ils se souviennent des choses passées, mais oublient ce qu'ils ont déjà dit. J'ai vu des récits bien plaisants devenir très ennuyeux dans la bouche d'un grand personnage, chacun ayant déjà entendu cela cent fois! (MONTAIGNE Ex. de B, I, 9, § 7.).

É necessário atentar este ponto: a primeira frase, que prossegue os parágrafos que condenaram a inventio e a narratio, fala de como deveria ser um bom final da exposição. Mas não se trata de condenar o efeito das palavras (a persuasão) em nome da verdade, ao contrário: o problema são os efeitos indesejados de uma dispositio deficiente, devido a uma espécie de perversão ("os velhos perigosos") que opera sobre a inventio (memória) e a narratio (das "coisas passadas"), estragando a expositio no final. Poderíamos dizer então que, de uma versão para outra dos Essais, aparece uma condenação progressiva e feroz à retórica. Só isso? Eu diria que não. Poderíamos dizer que, mais do que uma condenação, trata-se de uma crítica da retórica? Talvez. Pois seria uma crítica no sentido de reflexão e julgamento que não é totalmente visível no texto final sem considerar o processo conjunto da leitura e da escrita.

Ora, a meu ver, em Dos mentirosos Montaigne trabalha o problema da memória em relação às narrativas, e problematiza o tema da palavra em relação à consciência. Em um século saturado de crônicas, não é casual que as narrativas adquiram destaque. Porém, o lugar subalterno que as narrativas têm no projeto dos Essais permitiria a Montaigne ler as narrativas alheias sob uma perspectiva divergente da maioria dos seus contemporâneos, e com certeza totalmente afastada dos historiadores à moda (Cf. COSTA LIMA, 2006, para um desenvolvimento mais amplo deste ponto relacionado com a Escola de Pasquier). Por outro lado, o problema da narrativa e da memória se conectaria com o Eu autocentrado, i.e. que o surgimento do Eu psicologicamente orientado é concomitante a uma reflexão sobre a memória como instrumento da consciência e de seu veículo por excelência - o discurso: «somente pela palavra é que somos homens e nos entendemos» (MONTAIGNE, I, 9, p. 56). Se o Eu-movente se apresenta finalmente na forma do ensaio, no modelo digressivo da sua própria escrita - L'autres forment l'homme; je le recite. - , parece curiosa essa progressiva "crítica da retórica" que, ademais, envolveria as relações entre narrativa e Eu. 
Mas o concreto é que nada mais se diz sobre a memória em Dos mentirosos. Com os acréscimos de 1588 que continuam aos já analisados, Montaigne prefere retornar ao tema de 1580, estabelecendo um contraponto mais forte com a condenação moral da mentira. Esses parágrafos não receberam acréscimos no Exemplar de Bordeaux podemos supor que depois de criticar a retórica "tecnicamente" (por assim dizer), a vinculação com a mentira completava a condenação. Resulta instigante (e quase herética) a formulação de que a verdade é limitada enquanto o «reverso da verdade e o campo da ação da mentira não comporta limites» (MONTAIGNE I, 9, p. 57). E ainda acrescenta, como os pitagoristas, que a mentira seria «infinita».

A única evidência é que o autor evita a condenação moral que vai fazer em 1588 no ensaio sobre as mentiras, e desvia o assunto para suas leituras dos outros - que no começo, sintomaticamente, vinculam viagens, relações sociais, e instrução de si. Ainda mais: levando em conta os oblíquos caminhos da memória que Montaigne descreve no ensaio sobre a mentira, poderíamos pensar que, quando o Sujeito está sujeitado (servidão, embaixadas, etc.), mesmo nesses casos estaria operando o problema do Eu-movente na reprodução dos ditos como narrativas, daí a passagem da verdade "pura e simples" (e limitada) para uma forma da ética capaz de controlar algo desse território infinito da mentira, i.e., tentar definir o que seria a fidelidade.

Por isso, quando reconsideramos o texto de 1580 , o parágrafo seguinte deste ensaio sobre os embaixadores pode se revelar ainda mais complexo do que parece: quando ele lê histórias, «gênero que a tantos apetece hoje em dia» (MONTAIGNE, I, 17, p. 86), tem por hábito atentar para quem escreve, avalia o estilo e a linguagem, etc. Recorro mais uma vez a Limites da Voz: "encarecimento do testemunho" e "olhar fidedigno" como consequência da centralização do indivíduo antes que a nova Lei esteja sólida. Volto agora para o fragmento sobre os embaixadores e intuo: (a) a mediação da palavra (testemunho de embaixadores) e (b) fidelidade dos servidores ao dito («reproduzir fielmente tudo, tal e como se apresentou, a fim de que o senhor tenha a liberdade de ordenar, apreciar e escolher»). Isso é coerente com o ideal do $\mathrm{Eu}$, mas não é suficiente. Pois, quando retomamos as mudanças de 1580 para 1588 , poderíamos pensar que a concepção dos "fatos" já é mais complexa: eles devem ser procurados a partir de um quebra-cabeça que exige imbricar "dados" em "ditos". Em definitiva, uma interpretação sistemática, não uma exegese e nem uma antiexegese. 
O enorme peso que tem o tema da interpretação no último ensaio (III, 13) não pode ser casual. Por isso, as respostas provisórias àquelas duas perguntas formuladas na seção II, poderiam ser:

a) A interpretação em Montaigne muda ao longo das diversas edições dos Essais. Essa mudança da forma de interpretação não ocorre no momento da escrita original no caso dos Livros I e II, mas nos intervalos entre a edição de 1580 e 1588 , e entre 1588 e 1592. Sobre o Livro III, não sabemos.

b) A mudança na forma de interpretação se produz, primeiramente, a partir da leitura de seus próprios Livros I e II. Em uma segunda instância, a escrita original dos ensaios do Livro III teria modificado de novo a interpretação da própria obra anterior. Somente depois de que a interpretação tenha variado sobre a auto-interpretação, começa a se desenvolver uma mudança na hétero-interpretação (uma outra interpretação dos textos alheios).

A primeira concepção de interpretação dos textos alheios é, certamente, contraposta à exegese, mas também é bastante rudimentar porque só elimina, tira da frente, os ornamentos retóricos segundo uma coerência que estaria por fora dos textos. A última concepção de interpretação também é antirretórica, mas os livros já são um tipo de fato, pois a leitura combina dados com ditos aceitando que o fato puro existe, embora esteja longe demais no tempo para ser conhecido verdadeiramente. É, portanto, uma coerência por dentro dos textos o que procuraria Montaigne. Recalco a importância disso, pois é fundamental para a concepção da história em Montaigne. Em outras palavras: ao Eumovente corresponde uma visão na qual o fato sempre está mediado pela escrita, porquanto não existe possibilidade de fidelidade no testemunho, com ou sem retórica.

Em apoio a essa ideia, duas citações. Pertencem precisamente a II, 10 Dos livros, que conta as preferências de leitura de Montaigne, e no qual achamos a maior quantidade de informações sobre a sua concepção da escrita da história. É, aliás, um dos textos com menor número de acréscimos. Ainda mais, a parte correspondente à história não se modifica ao longo das edições, ficando sempre quase idêntica à publicada em 1580 . Há, porém, duas rasgaduras (!) que Montaigne faz sobre o Exemplar de Bordeaux. Por isso, na edição de 1595 essas frases foram apagadas. Ei-las aqui: 
[Et les historiens les plus recommandables sont ceux qui savent de quoi ils parlent, soit qu'ils aient participé aux faits qu'ils racontent, soit qu'ils aient été les proches de ceux qui les ont dirigés.] (MONTAIGNE 1580 e [Ex. de B.], II, 10, § 33). ${ }^{11}$

[Si même ils n'avaient pas vu de leurs propres yeux ce qu'ils racontaient, ils avaient au moins cet avantage d'avoir fait l'expérience de situations semblables, ce qui rendait leur jugement plus sûr.] (MONTAIGNE 1580 e [Ex. de B.], II, 10, § 35). ${ }^{12}$

Ambas apontam para o estatuto do testemunho, mas seria apressado dizer que Montaigne quis mudar em direção a uma ideia da história na qual o testemunho seja impossível. Coloquemos essas citações perdidas no contexto dos três parágrafos onde apareciam. ${ }^{33}$ Certamente, o

11 [E os historiadores mais recomendáveis são os que sabem do que falam, seja por que eles tenham participado dos fatos que eles contam, seja por que eles tenham sido próximos dos que os conduziram.]

12 [Mesmo que eles não tenham visto com seus próprios olhos o que contaram, eles tiveram ao menos esta vantagem de terem feito a experiência de situações semelhantes, o qual rende mais certeza ao o seu julgamento.]

13 É necessário transcrevê-las de maneira completa para entender o argumento. (A tipografia normal corresponde à edição de 1580; a sublinhada e a itálica aos textos apagados e acrescentados, respectivamente, no Exemplar de Bordeaux.) § 33. Ceux qui se situent entre les deux, et qui sont les plus courants, nous gâtent tout. Ils veulent nous mâcher le travail: ils s'autorisent donc à juger, et à faire pencher l'Histoire du côté de l'opinion qu'ils en ont. Car dans la mesure où leur jugement penche d'un côté, ils ne peuvent pas s'empêcher de modeler et conformer leur narration selon ce pli. Ils se mettent donc à choisir les choses dignes d'être connues, et nous cachent souvent telle ou telle parole ou action privée qui nous informerait bien mieux. Ils escamotent comme des choses incroyables les choses qu'ils ne comprennent simplement pas; et peut-être aussi d'autres encore parce qu'ils ne savent pas les formuler en bon latin ou bon français. Qu'ils fassent hardiment étalage de leur éloquence et de leurs raisonnements, qu'ils jugent de leur point de vue, mais qu'ils nous laissent à nous aussi de quoi juger après eux, et donc qu'ils n'altèrent ni ne fassent disparaître rien, par leurs choix et leurs coupures, de la matière elle-même, mais qu'ils nous la restituent pure et entière, avec toutes ses dimensions. [Et les historiens les plus recommandables sont ceux qui savent de quoi ils parlent, soit qu'ils aient participé aux faits qu'ils racontent, soit qu'ils aient été les proches de ceux qui les ont dirigés.] § 34. Le plus souvent, notamment à notre époque, on choisit pour cette fonction d'historien des gens du peuple, pour la seule raison qu'ils savent bien parler, comme si nous cherchions à apprendre la grammaire dans leurs livres! Et ils ont bien raison de ne se soucier que de cela, n'ayant été engagés que pour cela, et n'ayant mis en vente que leur babil. À force de beaux mots, ils nous confectionnent un beau gâteau avec les bruits qu'ils récoltent aux carrefours. § 35. Les seuls ouvrages historiques qui vaillent sont ceux qui ont été écrits par ceux-là mêmes qui étaient alors " aux affaires », ou qui participaient à leur conduite, ou à la rigueur ceux qui ont la chance d'en conduire d'autres du même genre. C'est le cas de presque tous les ouvrages 
resultado do texto final é a diminuição da importância da percepção e a maior definição do estatuto do testemunho. Por que?

$\mathrm{O}$ alvo deste fragmento são os historiadores contemporâneos. Em $\S 33$ estabelece sua luta contra a retórica em favor da escrita nua e sem ornamentos. Em $\$ 34$ fustiga os litterati que exercem seu oficio com essa retórica. Em $\$ 35$ coloca o modelo de escrita da história dos antigos. O texto rasgado primeiramente não é adequado para esse lugar; nessa posição, poderia indicar que ser testemunha dos fatos é condição suficiente para historiá-los simplesmente. Por isso, o que se soma ao estatuto do testemunho em \$35 é o requisito da autoridade: além de ver, é preciso conhecer o assunto por ser um daqueles que "dirigem”. Então, a mera percepção de estar não é suficiente, é preciso participar das decisões dos fatos. Tal é a sutil diferença em relação à versão do primeiro parágrafo rasgado. Por outro lado, o acréscimo ajusta esse requisito: poderiam não ter participado ativamente das decisões, mas sim deveriam ter a experiência de uma situação similar. Porém, quando lemos agora toda a sentença, com o acréscimo do ajuste, também fica mais fraca a condição primeira da presença. A percepção por si só já não serve de jeito nenhum, pois observemos o que é anulado: "ver com os próprios olhos" e a palavra "fait", que passa a ser "affaire". Conclusão: a ênfase na nova leitura para o modelo de escrita da história recai na sentença que culmina no parágrafo $\S 35$. Nessa frase, Montaigne afirma que só é possível estar livre de "erros" quando os historiadores-testemunhas forem mais de um. Mas atenção: pode haver "erros leves", ou contradições por "fatos muito obscuros". Daí que o fato puro seja inatingível, e que a escrita da história nunca possa ser fiel. O máximo que se consegue é uma leitura que precisa de múltiplas mediações (escritos de várias testemunhas ou historiadores) para aproximar-se do fato. Isso equivale a dizer que, para o leitor da história, o fato é duplo: aquele puro, e este material (o livro que está lendo). Todo leitor de história é um pouco historiador.

Daí, talvez, que o problema se manifeste com esclarecedora insistência quando são referidas as crônicas vinculadas ao Novo Mundo.

\footnotetext{
historiques des Grecs et des Romains. Car plusieurs témoins oculaires ayant écrit sur le même sujet (ce qui se produisait en ce temps-là où la grandeur et le savoir étaient souvent mêlés dans une même personne), s'il s'y trouve des fautes, elles ne peuvent être que très légères, et concerner des faits très obscurs. [Si même ils n'avaient pas vu de leurs propres yeux ce qu'ils racontaient, ils avaient au moins cet avantage d'avoir fait l'expérience de situations semblables, ce qui rendait leur jugement plus sûr.] (MONTAIGNE 1580 e [Ex. de B.], II, 10, § 33-34-35)
} 
Sabemos, por exemplo, que em 1580 Montaigne tinha lido a obra de Jean de Léry, mas também não tinha lido a História... de Gomara. Isto se deduz das referências ao Novo Mundo onde aparecem os espanhóis, só a partir da edição de 1588. Muito provável é que Montaigne soubesse que Gomara nunca esteve na América, como pode ser deduzido de um recente estudo sobre as duas traduções de Gomara para o francês (Gerbault, 2003). Entretanto, antes da segunda edição dos Essais, Montaigne só poderia ter consultado a de Martin Fumée (1568). A outra, de Le Breton (1588), tem a particularidade de ser mais fiel a Gomara e reduplicar o elogio a Hernán Cortés. Portanto, no momento de escrever Des Coches (III, 6), Montaigne dispunha de duas versões radicalmente diferentes, além da tradução de Las Casas e da leitura da História... de Oviedo (Cf. Lestringant, 1997). Que Montaigne não tenha modificado os §33-34-35 em 1588 dever-se-ia à força condenatória do \$34. Com efeito, até então, Montaigne sabia que um literatti como Gomara não tinha ido à América. Devido a isso, em seu processo de releitura não teria se apercebido de que a presença perceptual do historiador testemunha era suficiente para ser "mais recomendável". Circa 1592, porém, tudo é diferente. Oviedo e outros como Bernal Díaz estiveram no Novo Mundo, e ainda persistiam nos ornatos. Então, Montaigne faz a emenda que nuança o fato puro na história e regulamenta as testemunhas e sua leitura.

Outra observação instigante retoma o assunto da crítica da retórica, agora de maneira empírica sobre os principais ensaios referidos ao Novo Mundo. Concordo com Costa Lima (2006) na diferença entre Dos canibais (I, 31) e Dos coches. O primeiro funciona como uma alegoria. Mas o segundo é problemático. Permito-me fazer duas constatações breves: (a) Montaigne coloca na boca do Inca Atahualpa um discurso que não se corresponde com suas "fontes" (?); (b) muda o final do relato. No caso (a), sabendo que não pôde ter acesso às palavras verdadeiras, age como os amados historiadores antigos (p.e. Tucídides) e inventa o discurso provável. Ora, isso seria contraditório com o ideal da sua escrita da história, exceto pelo fato de que ele não escreve uma história... então, o que escreve? Se é uma peça de denúncia, trata-se de um elemento retórico chamado evidentia (pôr perante os olhos). Mencionemos ainda que outras referências à conquista espanhola, em outros ensaios, cumprem diferentes funções (como aquela do final do I, 30 que serve para introduzir o tema dos canibais e também foi acrescentada depois de 1580). Quanto ao ponto (b), lembremos a condenação à retórica realizada em Dos mentirosos. Sabendo que o final é o clímax da narratio retórica e o ponto que concede o sentido teológico, Montaigne acaba seu Des coches com um episódio que é deliberadamente antialegórico. Além 
disso, reorganiza toda a dispositio para que a tão primorosa construção de Gomara caia por terra antes do que o Inca. O curioso é que o recurso a um final similar tinha sido usado por ele em Dos canibais, porém neste outro caso com a intenção de efetuar uma alegoria. Em síntese, Montaigne rejeita o modelo retórico em conjunto, mas se aproveita dos seus truques para outros fins. Por isso, creio que seja atinada e produtiva a observação de Costa Lima (2006) a respeito do importante estúdio de Mendiola (2003): mesmo na hegemonia do modelo retórico, este não seria homogêneo, apresentaria fissuras.

Porém, o "mal-estar da retórica" não é exclusivo de Montaigne. O soldado Bernal Díaz também se queixa da História... de Gomara, acusando-a de retórica! Mas, neste caso, o protesto tem uma motivação material concreta (é um testemunho); outra coisa é quando deve escrever, pois seria absurdo dizer que Bernal Diaz vai redigir seu livro como se não soubesse o pouco que sabe (armar seu texto retoricamente). De todas as maneiras, talvez Montaigne não esteja tão longe de Bernal Diaz como se poderia pensar. Um por excesso, outro por falta, ambos sentiam o mesmo mal-estar da retórica.

\section{REFERÊNCIAS BIBLIOGRÁFICAS}

BARTHES, Roland. “A retórica antiga”. In: A aventura semiológica. Lisboa: Edições 70, 1987.

COSTA LIMA, Luiz. "Montaigne: a história sem ornatos". In: Revista Fênix. Revista de História e Estudos Culturais. Ano III, Vol. 3, no. 2, abril-junho de 2006. Disponível em: www.revistafenix.pro.br

. Limites da voz. Rio de Janeiro: Topbooks, 2005.

DOLABELA, Pedro. "A teoria da literatura como teoria da modernidade em Limites da voz, de Luiz Costa Lima”. XEROX, Pós-graduação em Letras da UERJ. Curso do Prof. Luiz Costa Lima. Rio de Janeiro: 2005.

FOUCAULT, Michel. Las palabras y las cosas. México: Siglo XXI, 1970.

GERBAULT, Matthieu. López de Gómara dans les controverses sur le Nouveau Monde: les traductions françaises de la Historia general de las Indias y conquista de Mexico. Édition critique et commentaire comparé. Paris: Ecole National de Chartes. Tese de defendida em 2003. Resumo in: http://theses.enc.sorbonne.fr/document79.html. Acesso em janeiro de 2005.

GIDE, André. "Montaigne". In: MONTAIGNE, Michel de. O pensamento vivo de Montaigne. São Paulo: Livraria Martins Editora, 1953. Vols. 1 e 2. Tradução de Sérgio Milliet. 
GUMBRECHT, H. U.. Corpo e forma. Rio de Janeiro: EdUERJ, 1998.

LESTRINGANT, Frank. O canibal: grandeza e decadência. Brasília: Editora UnB, 1997.

MENDIOLA, Alfonso. Retórica, Comunicación y Realidad: la construcción retórica de las batallas en las crônicas de la Conquista. México DF: Universidad Iberoamericana, 2003.

MERLEAU-PONTY, Maurice. “Lecture de Montaigne”. In: Signes. Paris: Gallimard, 1960.

MILLIET, Sérgio. "Vida e obra”. In: MONTAIGNE, Michel de. Ensaios. São Paulo: Editora Nova Cultural, 200o. Vol. 1.

MONTAIGNE, Michel de. Ensaios. São Paulo: Editora Nova Cultural, 20oo. Vols. 1 e 2. Tradução de Sérgio Milliet. . Ensayos. Buenos Aires: Losada, 1951.

. Les Essais. Livres I et II. Versão eletrônica in progress, 2004-2006. Edição de Guy de Pernon. In: http://homepage.mac.com/guyjacqu/index.html. Acesso em fevereiro de 2006.

. O pensamento vivo de Montaigne. São Paulo: Livraria Martins Editora, 1953. Vols. 1 e 2. Tradução de Sérgio Milliet.

MORINEAU, Michel. O século XVI, 1492-1610. Lisboa: P. Dom Quixote, 1980.

TAYLOR, Charles. Sources of Self. Cambridge: Harvard University Press, 1989. Tradução para o português: As fontes do self. São Paulo: Edições Loyola, 1997.

TODOROV, Tzvetan. "Esplendor e miséria da retórica”. In: Teorias do símbolo. Lisboa: Edições 7o, s/d. 
